\title{
Neuronal Mechanisms of Respiratory Pattern Generation Are Evolutionary Conserved
}

\author{
Elenia Cinelli, ${ }^{1,2}$ Brita Robertson, ${ }^{2}$ Donatella Mutolo, ${ }^{1}$ Sten Grillner, ${ }^{2}$ Tito Pantaleo, ${ }^{1}$ and Fulvia Bongianni ${ }^{1}$ \\ ${ }^{1}$ Department of Physiological Sciences, University of Florence, I-50134 Florence, Italy, and ${ }^{2}$ The Nobel Institute for Neurophysiology, Department of \\ Neuroscience, Karolinska Institute, SE-17177 Stockholm, Sweden
}

\begin{abstract}
A brainstem region, the paratrigeminal respiratory group (pTRG), has been suggested to play a crucial role in the respiratory rhythm generation in lampreys. However, a detailed characterization of the pTRG region is lacking. The present study performed on isolated brainstem preparations of adult lampreys provides a more precise localization of the PTRG region with regard to both connectivity and neurochemical markers. pTRG neurons projecting to the vagal motoneuronal pool were identified in a restricted area of the rostral rhombencephalon at the level of the isthmic Müller cell $\mathrm{I}_{1}$ close to sulcus limitans of His. Unilateral microinjections of lidocaine, muscimol, or glutamate antagonists into the pTRG inhibited completely the bilateral respiratory activity. In contrast, microinjections of glutamate agonists enhanced the respiratory activity, suggesting that this region is critical for the respiratory pattern generation. The retrogradely labeled pTRG neurons are glutamatergic and surrounded by terminals with intense substance P immunoreactivity. Cholinergic neurons were seen close to, and intermingled with, pTRG neurons. In addition, $\alpha$-bungarotoxin binding sites (indicating nicotinic receptors) were found throughout the pTRG area and particularly on the soma of these neurons. During apnea, induced by blockade of ionotropic glutamate receptors within the same region, microinjections of $1 \mu \mathrm{m}$ substance P or 1 mM nicotine into the pTRG restored rhythmic respiratory activity. The results emphasize the close similarities between the pTRG and the mammalian pre-Bötzinger complex as a crucial site for respiratory rhythmogenesis. We conclude that some basic features of the excitatory neurons proposed to generate respiratory rhythms are conserved throughout evolution.
\end{abstract}

\section{Introduction}

Studies on neuronal networks of the lamprey, a lower vertebrate that diverged from the main vertebrate line $\sim 560$ million years ago (Kumar and Hedges, 1998), proved to be highly useful to provide insights into the basic mechanisms of the central pattern generators (CPGs) (Grillner, 2006). Many of these networks as well as the basic features of neural organization have been conserved throughout vertebrate evolution (Grillner, 2003; Mutolo et al., 2007, 2010; Robertson et al., 2007; Kinkead, 2009; Ericsson et al., 2011, 2013; Stephenson-Jones et al., 2011, 2012a,b).

The isolated brainstem of the adult lamprey spontaneously generates respiratory neuronal activity in vitro. The vast majority of respiratory motoneurons are located in the facial, glossopharyngeal, and especially the vagal nuclei, whereas the neural aggregate responsible for respiratory rhythm generation appears to be located in a region rostral to the trigeminal motor nucleus (Rovainen, 1977, 1979, 1983, 1985; Thompson, 1985; Russell,

\footnotetext{
Received Jan. 22, 2013; revised April 16, 2013; accepted April 16, 2013.

Author contributions: E.C., B.R., D.M., S.G., T.P., and F.B. designed research; E.C., B.R., D.M., and F.B. performed research; E.C., B.R., and S.G. analyzed data; E.C., B.R., S.G., T.P., and F.B. wrote the paper.

This study was supported by grants from the Ministry of Education, University, and Research of Italy, A. Menarini United Pharmaceutical Industries, Swedish Research Council Grants VR-M 3026 and VR-NT 6212007-6049, and research funds from the Karolinska Institute. We thank Dr Peter Wallén for preparing the confocal photomicrographs.

The authors declare no competing financial interests.

Correspondence should be addressed to Fulvia Bongianni, Department of Physiological Sciences, University of Florence, Viale G. B. Morgagni 63, I-50134 Florence, Italy. E-mail: fulvia.bongianni@unifi.it.

DOI:10.1523/JNEUROSCI.0299-13.2013

Copyright $\odot 2013$ the authors $\quad 0270-6474 / 13 / 339104-09 \$ 15.00 / 0$
}

1986; Bongianni et al., 1999, 2002, 2006; Guimond et al., 2003; Martel et al., 2007; Mutolo et al., 2007). Endogenously released excitatory amino acids, but not GABA and glycine, play a crucial role in the lamprey respiratory rhythm generation (Bongianni et al., 1999, 2006). The region rostral to the trigeminal motor nucleus, termed the paratrigeminal respiratory group (pTRG), is characterized by the presence of different types of respirationrelated neurons and is sensitive to opioids and substance $\mathrm{P}$ and very likely crucial for the respiratory rhythm generation (Mutolo et al., 2007, 2010). Furthermore, acetylcholine modulates respiratory rhythm under basal conditions and is also capable of maintaining rhythmic respiratory activity, when both fast excitatory and inhibitory neurotransmission are impaired. Both these effects are achieved through an action on $\alpha 7$ nicotinic acetylcholine receptors (nAChRs) of pTRG neurons (Mutolo et al., 2011). Consistent with previous findings obtained in rodent medullary slices in vitro (Del Negro et al., 2005; Feldman and Del Negro, 2006), lamprey respiratory activity is abolished by bath application of riluzole and flufenamic acid used to block the burstpromoting currents, i.e., the persistent $\mathrm{Na}^{+}$current $\left(I_{\mathrm{NaP}}\right)$ and the $\mathrm{Ca}^{2+}$-activated nonspecific cation current $\left(I_{\mathrm{CAN}}\right)$, respectively, but is restored by substance $\mathrm{P}$ microinjections into the pTRG (Mutolo et al., 2010).

Despite several recent reports concerning the pTRG region, an extensive characterization of the pTRG (Mutolo et al., 2011; Gariépy et al., 2012a,b) is still lacking with regard to detailed anatomical landmarks and neurochemical markers, including glutamate, substance $\mathrm{P}$, and acetylcholine. We show here the pre- 
cise location of pTRG by demonstrating that the respiratory activity is entirely blocked by microinjections of muscimol and other agents in a small region just dorsal to the isthmic reticular cells. This region contains glutamatergic neurons projecting to the vagal respiratory motor nucleus, cholinergic cells and terminals, and substance P terminals. The location of our pTRG corresponds to that of the dorsal part of the mesencephalic locomotor region (MLR) described by Gariépy et al. (2012b). We also show that the pTRG exhibits very close similarities to the mammalian pre-Bötzinger complex (preBötC).

\section{Materials and Methods}

Experiments were performed on a total of 32 young adult $(12-15 \mathrm{~cm})$ lampreys (Petromyzon marinus) of either sex. All animal care and experimental procedures were conducted in accordance with the Italian legislation and the official regulations of the European Communities Council on the use of laboratory animals (Directive 86/609/EEC). The study was approved by the Animal Care and Use Committee of the University of Florence, as well as by the Swedish local ethical committee (Norra Djurförsöksetiska Nämnd of Stockholm). During the investigation, all efforts were made to minimize animal suffering and to reduce the number of animals used.

\section{Anatomical experiments}

Experiments were performed on 16 lampreys. The dissection, injections, fixation, and sectioning of the lamprey brains were performed as described previously (Stephenson-Jones et al., 2011, 2012a). The animals were anesthetized with tricaine methansulfonate $(100 \mathrm{mg} / \mathrm{L}$; MS-222; Sigma-Aldrich) and transected caudally at the seventh gill. The dorsal skin, muscles, and cartilage were removed to expose the brain. During the dissection and the injections, the head was pinned down and submerged in ice-cooled physiological solution (in mM): $91 \mathrm{NaCl}, 2.1 \mathrm{KCl}, 2.6 \mathrm{CaCl}_{2}$, $1.8 \mathrm{MgCl}_{2}, 4$ glucose, and $23 \mathrm{NaHCO}_{3}$. The solution was continuously bubbled with $95 \% \mathrm{O}_{2} / 5 \% \mathrm{CO}_{2}$ to oxygenate and maintain the $\mathrm{pH}$ at 7.4.

Retrograde tracing. All injections were made with glass micropipettes (borosilicate, $1.5 \mathrm{~mm}$ outer diameter, $1.17 \mathrm{~mm}$ inner diameter), with a tip diameter of $10-20 \mu \mathrm{m}$. The micropipettes were fixed in a holder, which was attached to an air supply and a micromanipulator. Neurobiotin (20\% in distilled water; Vector Laboratories) was pressure injected $(\sim 50 \mathrm{nl})$ unilaterally into the region of vagal nuclei, in which the vast majority of respiratory motoneurons are located. Injections were made at two different adjacent sites along the vagal nucleus to affect as much as possible the entire population of respiratory motoneurons. The inactive dye Fast Green (0.2\%; Sigma-Aldrich) was added to the solution to aid visualization of the injected tracer. Texas Red-conjugated dextran at 3 $\mathrm{kDa}$ ( $25 \%$ in distilled water; Invitrogen) was injected unilaterally into the same location in the animals that were processed for histochemical detection of $\alpha 7$ nAChRs.

Dissection and histology. After injections, the heads were kept submerged in the physiological solution in the dark at $4^{\circ} \mathrm{C}$ for $24 \mathrm{~h}$ to allow retrograde transport of the tracers. The brains were then dissected out of the surrounding tissue and fixed by immersion in $4 \%$ Formalin and $14 \%$ saturated picric acid in $0.1 \mathrm{~m}$ phosphate buffer (PB), $\mathrm{pH} 7.4$, for 12-24 h, after which they were cryoprotected in $20 \%$ sucrose in PB for 3-12 h. Transverse $20-\mu \mathrm{m}$-thick sections were made using a cryostat, collected on gelatin-coated slides, and stored at $-20^{\circ} \mathrm{C}$ until additional processing. For glutamate immunohistochemistry, the brains were fixed by immersion in $4 \%$ Formalin, $1 \%$ glutaraldehyde, and $14 \%$ of a saturated solution of picric acid in PB. The brains were postfixed for $24-48 \mathrm{~h}$ and cryoprotected as described above.

Immunohistochemistry. All primary and secondary antibodies were diluted in $1 \%$ BSA, $0.3 \%$ Triton X-100 in $0.1 \mathrm{M}$ PB. For immunohistochemical detection of glutamatergic neurons within the pTRG, sections were incubated overnight with a polyclonal rabbit anti-glutamate antibody (1:600; AB133; Millipore Corporation). After a thorough rinse in $0.01 \mathrm{M}$ PBS, the sections were incubated with Cy3-conjugated donkey antirabbit IgG (1:250; Jackson ImmunoResearch) and Alexa Fluor-488conjugated streptavidin (1:1000; Jackson ImmunoResearch) for $3 \mathrm{~h}$, rinsed in PBS, and coverslipped with glycerol containing 2.5\% diazabicyclanooctane (Sigma-Aldrich).

For immunohistochemical detection of substance P in the pTRG, sections were incubated overnight with a polyclonal guinea pig antisubstance P antiserum (1:200; T-5019, MAB356; Peninsula Laboratories), raised against synthetic substance P conjugated to BSA. Sections were subsequently incubated with $\mathrm{Cy} 3$-conjugated donkey anti-guinea pig IgG (1:500; Jackson ImmunoResearch) and Alexa Fluor-488conjugated streptavidin (1:1000; Jackson ImmunoResearch) for $3 \mathrm{~h}$.

For the immunohistochemical detection of choline acetyltransferase (ChAT), a marker for cholinergic cells, within the pTRG, sections were incubated overnight with a polyclonal goat anti-ChAT (1:100; AB144P; Millipore Corporation) raised against ChAT isolated from human placenta. Sections were subsequently incubated with a mixture of Neurotrace deep-red fluorescent Nissl stain (1:1000; Invitrogen), Cy3conjugated donkey anti-goat IgG (1:500; Jackson ImmunoResearch), and Alexa Fluor-488-conjugated streptavidin (1:1000; Jackson ImmunoResearch) for $3 \mathrm{~h}$.

For the detection of $\alpha 7 \mathrm{nAChRs}$ within the pTRG, sections were incubated with biotinylated $\alpha$-bungarotoxin (1:750; B1196; Invitrogen) for $4 \mathrm{~h}$. Sections were subsequently incubated with a mixture of Neurotrace deep-red fluorescent Nissl stain (1:1000; Invitrogen) and Alexa Fluor488-conjugated streptavidin (1:1000; Jackson ImmunoResearch) for $3 \mathrm{~h}$.

The specificity of antibodies used is known from previous studies in the lamprey (Stephenson-Jones et al., 2011, 2012a). The biotinylated $\alpha$-bungarotoxin has shown specificity for $\alpha 7$ nAChRs (Csillik et al., 1999; Jones and Wonnacott, 2004).

Analyses. Retrogradely labeled neurons as well as ChAT-positive cells were counted on transverse sections encompassing the pTRG region on each side. Every second section was counted to prevent double counting of single cells. However, this procedure could lead to an underestimation of the total number of counted neurons. Photomicrographs of key results were taken with an Olympus XM10 (Olympus Sverige) digital camera. Illustrations were prepared in Adobe Photoshop CS2 and CS4 (Adobe Systems). Images were only adjusted for brightness and contrast. Confocal $Z$-stacks of the sections were obtained using a Carl Zeiss laser scanning microscope 510 equipped with a $60 \times$ oil-immersion objective (numerical aperture 1.35), and the projection images were processed using the Carl Zeiss LSM software and Adobe Photoshop CS2 and CS4.

\section{Electrophysiological experiments}

Animal preparation. Experiments were performed on 16 lampreys. Animal preparation and experimental procedures were similar to those described in previous reports (Bongianni et al., 1999, 2002, 2006; Mutolo et al., 2007, 2010, 2011). The animals were anesthetized with tricaine methanesulphonate (100 mg/L; MS-222, Sigma-Aldrich) and transected below the gills. Muscles and connective tissues were removed, and the isolated brain-spinal cord was mounted dorsal-side up in a Sylgard-lined recording chamber continuously perfused with a cold solution using a peristaltic pump. The chamber volume was $3.0 \mathrm{ml}$, and the perfusion rate was set at $2.5 \mathrm{ml} / \mathrm{min}$. Bath temperature was maintained at $9-10^{\circ} \mathrm{C}$. The solution flowed from a reservoir and had the following composition (in $\mathrm{mm}$ ): $91 \mathrm{NaCl}, 2.1 \mathrm{KCl}, 2.6 \mathrm{CaCl}_{2}, 1.8 \mathrm{MgCl}_{2}$, 4 glucose, and $23 \mathrm{NaHCO}_{3}$. The solution was continuously bubbled with $95 \% \mathrm{O}_{2}-5 \% \mathrm{CO}_{2}$ to oxygenate and maintain the $\mathrm{pH}$ in the bath at 7.4. The brain was exposed dorsally, and the choroid plexus was removed; the brain tissue rostral to the optic tectum was cut and removed. Caudally, a transection was made caudal to the obex, maintaining a minimum length of spinal cord to hold the brainstem preparation. The isolated brainstem of the adult lamprey spontaneously generates respiratory neuronal activity in vitro (fictive respiration); this activity closely resembles that underlying the respiratory behavior of intact animals (Rovainen, 1977, 1983; Thompson, 1985; Russell, 1986; Bongianni et al., 1999, 2002, 2006; Martel et al., 2007; Mutolo et al., 2007, 2010, 2011). Recordings of respiration-related neurons within the pTRG and microinjections into this region as well as neighboring sites were performed under microscope control (Stemi 2000; Carl Zeiss). These maneuvers were facilitated by cutting the roof of the isthmic region along the midline, spreading the alar plates laterally and pinning them down. In agreement with previous reports (Mutolo et 
al., 2007, 2010, 2011), these procedures had no significant effect on respiratory activity.

Recording procedures. Efferent respiratory activity was recorded bilaterally from the vagal nerves by means of suction electrodes. The signals were amplified, full-wave rectified, and integrated (low-pass filter, $10 \mathrm{~ms}$ time constant). In control trials, brainstem preparations spontaneously produced a stable and regular fictive respiratory rhythm for at least $12 \mathrm{~h}$ (Thompson, 1985; Bongianni et al., 1999, 2002, 2006; Mutolo et al., 2007, 2010, 2011). Extracellular neuronal activity was recorded with fine $(0.1$ $\mathrm{mm}$ shaft diameter) tungsten microelectrodes (5 $\mathrm{M} \Omega$ impedance at 1 $\mathrm{kHz}$ ) and processed in the same way as vagal activity. The obex was used as a standard point of anatomical reference to evaluate coordinates of recording and microinjection sites. In these preparations, neuronal activity was recorded from respiration-related neurons of the pTRG (1.8$2.0 \mathrm{~mm}$ rostral to the obex, $0.8-1.0 \mathrm{~mm}$ lateral to the midline, and $0.25-0.3 \mathrm{~mm}$ below the dorsal surface that, given the arrangement of our preparations in the electrophysiological experiments, corresponded to the tilted lateral wall of the IV ventricle). All the raw and integrated signals were acquired and analyzed by a personal computer equipped with an analog-to-digital interface $(50 \mathrm{kHz}$ sampling rate; Digidata 1200; Molecular Devices), and appropriate software (Axoscope; Molecular Devices) was used. Offline analysis was performed using Clampfit software (Molecular Devices).

Drug application and histology. Drugs were microinjected into the pTRG on the basis of both extracellular recordings and coordinates. The following drugs were used: 2 mM NMDA (a selective NMDA receptor agonist; Tocris Bioscience), $1 \mathrm{~mm}$ AMPA (a selective non-NMDA receptor agonist; Tocris Bioscience), $5 \mathrm{~mm}$ D-(-)-2-amino-5phosphonopentanoic acid (D-AP5; an NMDA receptor antagonist; Tocris Bioscience), $1 \mathrm{~mm}$ 6-cyano-7-nitroquinoxaline-2,3-dione (CNQX; a non-NMDA receptor antagonist; Tocris Bioscience), $0.2 \mathrm{~mm}$ muscimol

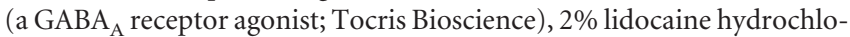
ride (a Na${ }^{+}$-channel blocker; Sigma-Aldrich), $1 \mu \mathrm{M}$ substance P (the endogenous agonist of neurokinin receptors; Tocris Bioscience), and 1 mM nicotine hydrogen tartrate salt (an nAChR agonist; Sigma-Aldrich). The drug concentrations were similar to those used in previous studies in lampreys (Ménard et al., 2007; Martel et al., 2007; Mutolo et al., 2010, 2011; Gariépy et al., 2012a). For additional considerations on the concentrations of neuroactive drugs, see Mutolo et al. (2007). All used drugs were dissolved in distilled water made up to a stock solution and stored as small aliquots in a freezer until use. Stock solutions were diluted in the perfusing solution to the final desired concentration immediately before microinjections.

Bilateral or unilateral microinjections $(0.5-1 \mathrm{nl})$ of different drugs were performed by means of glass micropipettes $(10-20 \mu \mathrm{m}$ tip diameter) and by applying pressure pulses of $50-100 \mathrm{~ms}$ with a Picospritzer (General Valve Corporation) connected to the injection pipette. The injected volume was estimated by measuring the diameter of a droplet ejected from the tip of the pipette. Bilateral microinjections were performed using a single micropipette that was withdrawn after the first microinjection and then introduced contralaterally for the second injection. The interval between the two microinjections was $\leq 20 \mathrm{~s}$. The inactive dye Fast Green $(0.2 \%)$ was added to the drug solution to visually assess the spread and the approximate localization of the injection. The microinjections were associated with the appearance of dye spots $(\sim 0.2$ $\mathrm{mm}$ diameter) confined to the investigated regions (Mutolo et al., 2007, 2011). Localization of the PTRG was judged on the basis of dye spot position with respect to the sulcus limitans of His. The depth of the injection was inferred from that of rhythmic extracellular neuronal activity previously recorded in each preparation. The depth of the injections was $\sim 0.3 \mathrm{~mm}$ below the dorsal surface (recordings from respiration-related neurons in the study by Mutolo et al., 2011). According to histological controls (Mutolo et al., 2007, 2011) and consistent with the diameter of the dye spots generated by the microinjections, the injected area has a diameter of $\sim 0.2 \mathrm{~mm}$, implying a spread of $\sim 0.1 \mathrm{~mm}$ in any direction from the injected site. Control microinjections of equal volumes of the vehicle solution with $0.2 \%$ Fast Green dye were also made. After each experiment, the brainstem was fixed (4\% Formalin in $0.1 \mathrm{M}$ $\mathrm{PB}, \mathrm{pH} 7.4$, overnight), cryoprotected with $30 \%$ sucrose, frozen, and cut at $20 \mu \mathrm{m}$ thickness on a cryostat. Coronal sections stained with cresyl violet were used for the histological control as described in previous reports (Mutolo et al., 2007, 2011), in which methodological considerations on the reliability of our microinjection technique have also been provided.

Data analyses. Respiratory frequency (cycles per minute), vagal burst duration (milliseconds, measured on raw activity), and peak amplitude of integrated vagal activity (taken as a reliable index of the intensity of vagal bursts, arbitrary units) were measured and averaged for $20 \mathrm{~s}$ both in the period immediately before the microinjections (control values) and at the time when the maximum response occurred. Average values of respiratory variables observed in control conditions and at the time when the maximum response occurred were considered for statistical analysis (SigmaStat; SPSS). Paired $t$ tests were used to evaluate changes in respiratory variables induced by each drug. Changes in respiratory variables were also expressed as percentage variations of control values. The number of preparations used in each set of drug challenges is indicated by $n$. All values are presented as means \pm SEM; $p<0.05$ was considered as significant.

\section{Results}

\section{Anatomical boundaries of the pTRG}

Unilateral injections of neuronal tracers (Neurobiotin, $n=12$; Texas Red-conjugated dextran, $n=4$ ) were performed into the vagal motoneuronal pool to retrogradely label neurons projecting to respiratory motoneurons. Retrogradely labeled neurons were round or bipolar, and the largest diameter of their soma varied from 10 to $24 \mu \mathrm{m}$. They were confined within a small portion of the rostral rhombencephalon/isthmic region in the dorsal aspect of the anterior rhombencephalic reticular nucleus (ARRN) at the level of the isthmic Müller cell $\mathrm{I}_{1}$, close to the sulcus limitans of His (Fig. 1 $A, B$ ). The location corresponds closely to that already reported in previous studies for the pTRG in our laboratory (Mutolo et al., 2007, 2011). In the present study, the pTRG region was always identified by means of retrograde tracing before the immunohistochemical or histochemical procedures. Retrogradely labeled neurons (Fig. 1) were consistently found in a region located from $\sim 30$ to $270 \mu \mathrm{m}$ lateral to the ventricular surface and extending rostrocaudally for $\sim 80 \mu \mathrm{m}$ with the lower boundary at the level of the rostral border of the trigeminal motor nucleus. The dorsoventral extent of this region was $\sim 200 \mu \mathrm{m}$. Examples of Neurobiotin-labeled neurons within the pTRG (green signal) and the injection site into the vagal motor nucleus (green signal) are shown (Fig. 1B,D). Labeled neurons were mostly ipsilateral to the motoneuronal injection, even if few cells were also encountered in the contralateral pTRG region (data not shown). Labeled fibers of pTRG neurons were seen crossing the midline through the basal plate at the level of the vagal motoneurons (Fig. $1 D$ ) and the roof of the isthmic region (see Fig. 4B). This latter finding is in agreement with that reported by Gariépy et al. (2012b). Neurobiotin injections labeled on average $26.0 \pm 1.5$ neurons in the ipsilateral pTRG and $4.3 \pm$ 0.6 neurons in the contralateral pTRG. Dextran injections labeled $23 \pm 1.1$ and $3.5 \pm 0.3$ neurons in the ipsilateral and contralateral pTRG, respectively. No labeling was found at the level of the trigeminal motor nucleus after injections into the vagal motor nucleus (Fig. 1C).

\section{Respiratory responses after blockade or activation of the pTRG}

To characterize the respiratory role of the PTRG region, several drugs were unilaterally microinjected to block or activate pTRG neurons (Fig. 2). A blockade of glutamate receptors (AMPA and NMDA) within PTRG was achieved by means of a unilateral 

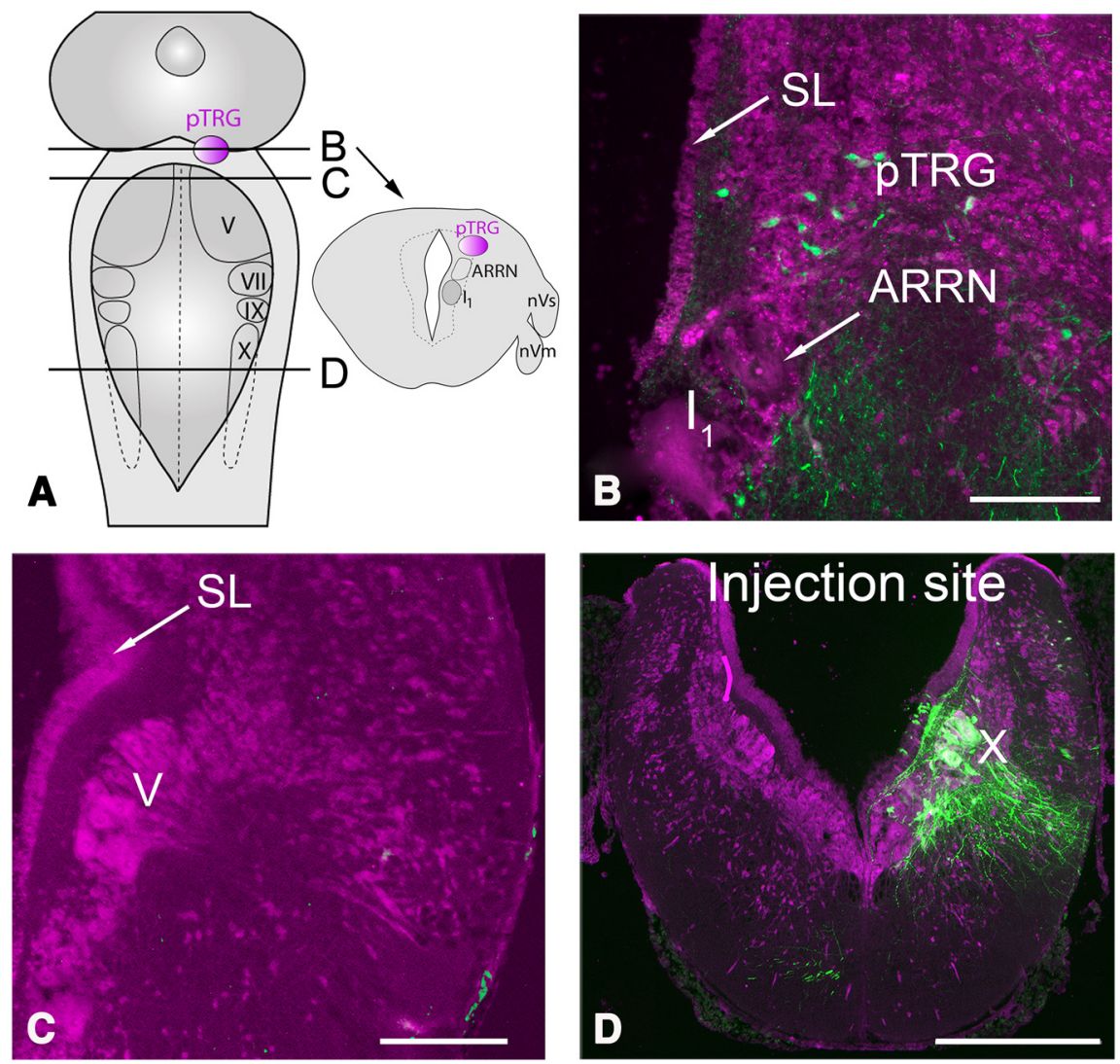

Figure 1. Distribution of retrogradely labeled neurons in the PTRG region of the lamprey. $\boldsymbol{A}$, Schematic illustration of a dorsal view of the lamprey mesencephalon/rhombencephalon showing the levels of the coronal sections illustrated in $\boldsymbol{B}-\boldsymbol{D}$ (unbroken lines) and the location of the PTRG (pink area). The PTRG location is also reported (pink area) on a schematic coronal section (arrow). $\boldsymbol{B}$, Photomicrograph of a transverse section of the isthmic region showing retrogradely labeled neurons (green signal) after injections of Neurobiotin into the vagal motoneuron pool. A population of labeled cells was found at the level of the anterior rhomboencephalic reticular nucleus close to the isthmic Müller cell $I_{1}$, in a region corresponding to the $p$ TRG. $C$, Section at the level of the trigeminal motor nucleus $\sim 60 \mu \mathrm{m}$ caudal to the section reported in $\boldsymbol{B}$ showing the absence of retrogradely labeled cells after tracer injections into the vagal motoneuron pool. $\boldsymbol{D}$, Photomicrograph of a transverse section of the caudal rhomboencephalon showing the site of Neurobiotin injection into the vagal motor nucleus (green signal). Note the small bundle of crossing fibers. All sections are counterstained with deep red fluorescent Niss $\mathrm{stain} . \mathrm{I}$, Isthmic Müller cell; $\mathrm{nVm}$, motor root of the trigeminal nerve; nVs, sensory root of the trigeminal nerve; SL, sulcus limitans of His; V, trigeminal motor nucleus; VII, facial motor nucleus; IX, glossopharyngeal motor nucleus; $X$, vagal motor nucleus. Scale bars: $B, C, 200 \mu \mathrm{m} ; D, 500 \mu \mathrm{m}$.

microinjection $(n=3)$ of $1 \mathrm{~mm}$ CNQX $(0.5-1 \mathrm{pmol})$ and $5 \mathrm{~mm}$ D-AP5 (2.5-5 pmol), which caused a complete suppression of the respiratory bursts within $1 \mathrm{~min}$ after the completion of the injections (Fig. 2A). In three additional preparations, unilateral microinjections of $0.2 \mathrm{~mm}$ muscimol, a selective agonist for the $\mathrm{GABA}_{\mathrm{A}}$ receptors $\left(0.1-0.2 \mathrm{pmol}\right.$; three trials), or the $\mathrm{Na}^{+}$channel blocker lidocaine (2\%, 34.6-69 pmol; three trials) into the PTRG area also abolished the respiratory activity within $1 \mathrm{~min}$ (Fig. 2B,C). These effects were bilaterally symmetrical (shown in Fig. $2 A$ for AMPA/NMDA receptor blockade). The duration of the apneic response for lidocaine ranged from 4 to $6 \mathrm{~min}$ and for the other drugs from 6 to $10 \mathrm{~min}$. Respiratory activity recovered gradually within $45 \mathrm{~min}$ after the injections.

Conversely, unilateral microinjections $(n=4)$ of the glutamate agonists AMPA ( $1 \mathrm{~mm}, 0.5-1 \mathrm{pmol})$ and NMDA ( $2 \mathrm{~mm}, 1-2$ pmol) into the pTRG region (Fig. $2 D$ ) increased the respiratory frequency from $63.5 \pm 3.6$ to $86.2 \pm 5.5$ cycles $/ \mathrm{min}(36.8 \pm 6.8 \%$; $t=4.40 ; \mathrm{df}=3 ; p<0.05)$ and the peak vagal activity $(26.8 \pm$ $6.8 \% ; t=3.71 ; \mathrm{df}=3 ; p<0.05)$ accompanied by changes in vagal burst duration from $30.1 \pm 2.5$ to $50.0 \pm 5.9 \mathrm{~ms}(68.7 \pm 19.4 \%$; $t=3.37 ; \mathrm{df}=3 ; p<0.05)$. These respiratory responses started within $30 \mathrm{~s}$ after completion of the injection and reached a maximum within 2 min. Respiratory activity recovered gradually within $15 \mathrm{~min}$ (Fig. 2D). Also in this case, the drug effects were bilaterally symmetrical. These excitatory effects were prevented (two trials) by microinjections of $1 \mathrm{~mm}$ CNQX/5 mM D-AP5 performed 2-3 min earlier at the same site.

Unilateral control microinjections of equivalent volumes of the vehicle solution containing $0.2 \%$ Fast Green at the responsive site (three trials) did not cause any obvious respiratory response. Similarly, unilateral microinjections of the drugs used in Figure 2 at sites outside pTRG, 400 $\mu \mathrm{m}$ or more away from the responsive region (CNQX/D-AP5, four trials; muscimol, three trials; lidocaine, three trials; AMPA/NMDA, three trials), failed to induce any change in respiratory activity (examples are illustrated in Fig. 3). These control microinjections were performed into the trigeminal motor nucleus or its lateral border, as well as at more rostral sites into the mesencephalic region. This indicates that the critical region for rhythmogenesis is limited to the area that contains pTRG and retrogradely stained neurons from the vagal motor nucleus (Fig. 1).

\section{Distribution of glutamate immunoreactivity in the PTRG}

The presence of glutamatergic neurons within the pTRG was investigated by double-labeling experiments $(n=4)$. Examples of retrogradely labeled neurons in pTRG identified by injections of Neurobiotin into the vagal motoneuron pool are illustrated in Figure $4 A-C$ (merged, Neurobiotin green plus glutamate immunoreactivity red signals). Figure $4, B_{1}$ and $B_{2}$, shows at higher magnification retrogradely labeled pTRG neurons (green signal) and glutamate immunoreactivity (red signal) in the same section. Some neurons displayed glutamate immunoreactivity without retrograde labeling. The merged image (Fig. $4 B_{3}$ ) shows that all retrogradely labeled pTRG neurons were immunoreactive for glutamate, and these results suggest that the pTRG projection neurons to the vagal nucleus are glutamatergic. However, we cannot exclude the presence of non-glutamatergic neurons in the pTRG region.

\section{Role of substance $P$ for $p$ TRG rhythmogenesis}

To corroborate previous findings supporting a rhythmogenic role of substance $\mathrm{P}$ during blockade of respiratory activity by bath coapplication of riluzole and flufenamic acid (Mutolo et al., 2010), we sought to examine the presence of substance P immunoreactivity $(n=4)$ within the PTRG region. Retrogradely labeled neurons located within the pTRG (Fig. $5 A_{1}$, green signal) were identified by injections of Neurobiotin into the vagal motoneuron region. Figure $5 \mathrm{~A}_{2}$ illustrates substance $\mathrm{P}$ immunoreactivity (red signal) in the same section. By merging the two 


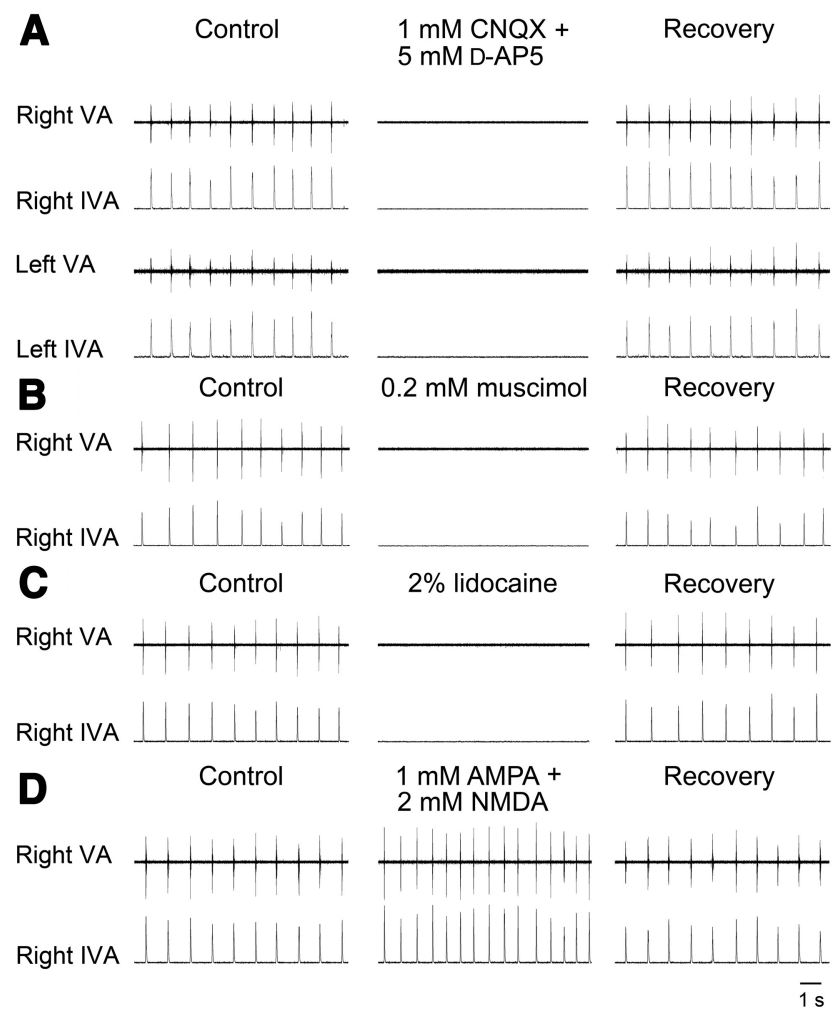

Figure 2. Examples of respiratory responses evoked by blockade or activation of pTRG region. $A$, Suppression of respiratory rhythmic activity $\sim 1 \mathrm{~min}$ after unilateral microinjections into the pTRG region of a mixture of $1 \mathrm{~mm}$ CNQX and 5 mM D-AP5. $\boldsymbol{B}, \boldsymbol{C}$, Similar effects on respiration induced by unilateral microinjections into the $\mathrm{pTRG}$ region of $0.2 \mathrm{~mm}$ muscimol or $2 \%$ lidocaine, respectively. $\boldsymbol{D}$, Increases in respiratory frequency and peak vagal activity $\sim 2 \mathrm{~min}$ after a unilateral microinjection of a mixture of $1 \mathrm{~mm}$ AMPA and $2 \mathrm{~mm} \mathrm{NMDA}$ into the pTRG. VA, Raw vagal nerve activity; IVA, integrated vagal nerve activity.

signals, we found that retrogradely labeled neurons were surrounded by intense substance $\mathrm{P}$ immunoreactivity (Fig. $5 A_{3}$ ). No substance $\mathrm{P}$-immunoreactive cell bodies were encountered within the pTRG.

We investigated whether the respiratory rhythm could also be restored during apnea induced by bilateral microinjections of 1 mM CNQX/5 mM D-AP5 into the pTRG. Bilateral microinjections of $1 \mu \mathrm{M}$ substance $\mathrm{P}(0.5-1 \mathrm{fmol})$ performed into the pTRG $(n=$ 3) $\sim 2$ min after the onset of apnea restored rhythmic respiratory activity within $1 \mathrm{~min}$ after the completion of the injections. The recovered vagal motor output was stable and regular for $\sim 4 \mathrm{~min}$ and resembled that observed during control conditions (Fig. 5B). Thereafter, the respiratory rhythmic activity faded out into apnea. The subsequent complete recovery was seen within $60 \mathrm{~min}$. Bilateral microinjections of $1 \mu \mathrm{M}$ substance $\mathrm{P}$ (three trials) into neighboring regions $0.4 \mathrm{~mm}$ or farther away from the pTRG (same control regions as reported above) were unable to restore rhythmic activity during apnea induced by the blockade of ionotropic glutamate receptors.

\section{Role of acetylcholine for pTRG rhythmogenesis}

Acetylcholine exerts excitatory influences on the respiratory activity through an action of $\alpha 7 \mathrm{nAChRs}$ agonists within the pTRG (Mutolo et al., 2011). Therefore, we explored whether cholinergic neurons and $\alpha 7 \mathrm{nAChRs}$ are present in, or in the vicinity of, the pTRG. In four preparations, retrogradely labeled neurons located within the pTRG (Fig. $6 A_{1}$, green signal) were identified by injections of Neurobiotin into the vagal motoneuron region (Fig.

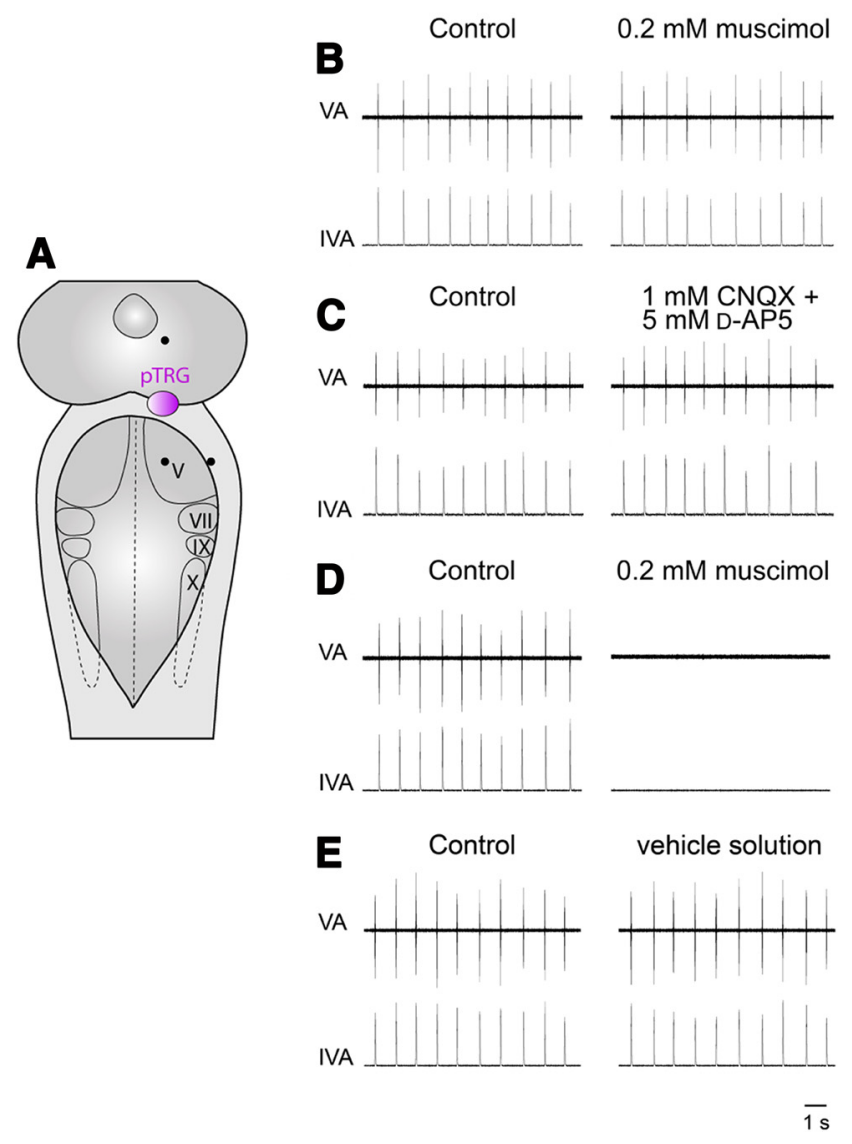

Figure 3. Unilateral control microinjections. $A$, Control injection sites $(\mathbf{O}) 0.4 \mathrm{~mm}$ or more away from the PTRG (pink area) shown on a schematic illustration of a dorsal view of the lamprey mesencephalon/rhombencephalon. $\boldsymbol{B}$, Absence of appreciable respiratory effects $\sim 1$ min after a unilateral microinjection of $0.2 \mathrm{~mm}$ muscimol at the lateral border of the trigeminal motor nucleus. C, Absence of obvious respiratory responses $\sim 1$ min after a unilateral microinjection of a mixture of $1 \mathrm{~mm}$ CNQX and $5 \mathrm{~mm}$ D-AP5 into the mesencephalic region. The drugs used failed to induce the characteristic effects elicited by unilateral microinjections into the PTRG in all the selected control sites. $\boldsymbol{D}$, The dramatic inhibitory effects on respiratory activity induced by a unilateral microinjection of $0.2 \mathrm{~mm}$ muscimol into the pTRG have also been illustrated for comparison. $\boldsymbol{E}$, Absence of obvious respiratory responses $\sim 1$ min after a unilateral microinjection of the vehicle solution into the PTRG. V, Trigeminal motor nucleus; VII, facial motor nucleus; IX, glossopharyngeal motor nucleus; $\mathrm{X}$, vagal motor nucleus; $\mathrm{VA}$, raw vagal nerve activity; IVA, integrated vagal nerve activity.

$6 A_{4}$ ). ChAT-immunoreactive neurons (red signal) in the same section are shown in Figure $6 A_{2}$. By merging the two signals, ChAT-positive neurons were consistently found to be located just ventral to, but also intermingled with, retrogradely labeled neurons (Fig. $6 \mathrm{~A}_{3}$ ). No retrogradely labeled pTRG neurons were immunoreactive for ChAT. ChAT-immunoreactive cells were small- to medium-sized neurons with a soma diameter ranging from 10 to $27 \mu \mathrm{m}$. On average, $14.2 \pm 1.6$ cholinergic neurons were found on each side of the brainstem sections. The inset at higher magnification in Figure $6 A_{3}$ shows that small ChATimmunoreactive structures, probably synaptic terminals, are in close apposition to a retrogradely labeled cell.

The histochemical expression pattern of $\alpha 7 \mathrm{nAChRs}$ in the pTRG region was investigated by using $\alpha$-bungarotoxin binding (Fig. $6 B$ ). Double-labeling experiments $(n=4)$ were performed in lampreys that received dextran injections (red signal) into the vagal motor nucleus (Fig. $6 B_{4}$ ) to define the region of retrogradely labeled neurons (Fig. $6 B_{1}$, red signal). Dextranlabeled neurons in the pTRG displayed features similar to 

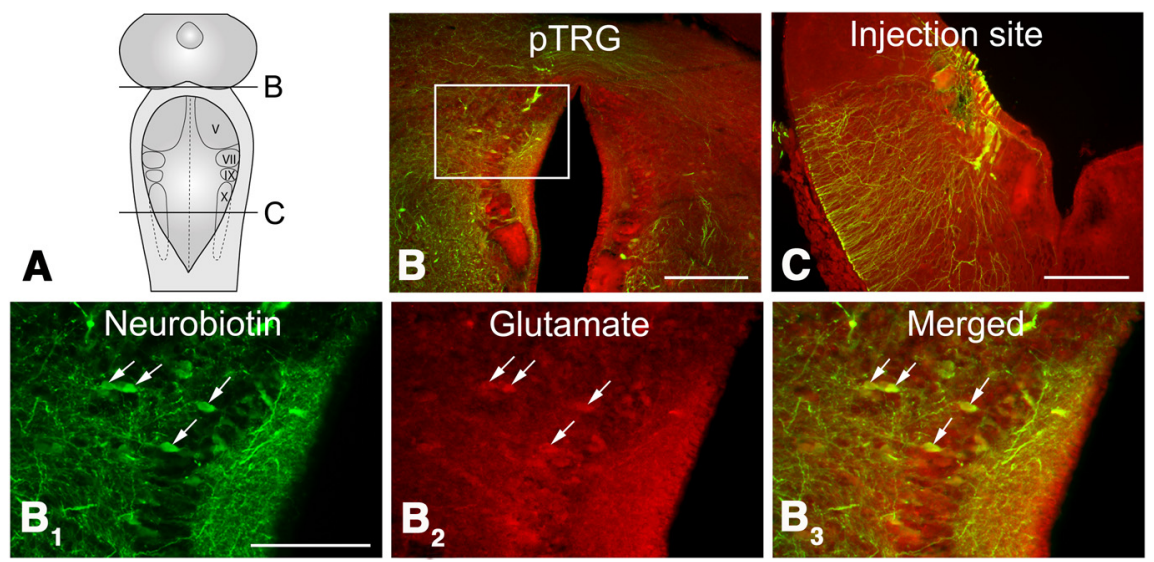

Figure 4. Distribution of glutamate immunoreactivity in the pTRG. $\boldsymbol{A}$, Schematic illustration of a dorsal view of the lamprey mesencephalon/rhombencephalon showing the levels of the coronal sections reported in $\boldsymbol{B}$ and $\boldsymbol{C}$ (unbroken lines). $\boldsymbol{B}$, Photomicrograph of a transverse section at the level of the isthmic area/rostral rhombencephalon showing retrogradely labeled neurons (merged, Neurobiotin green plus glutamate immunoreactivity red signals) in the pTRG region after injections of Neurobiotin into the vagal motoneuron pool. Labeled fibers can be observed crossing at the isthmic roof. $\boldsymbol{C}$, Transverse section of the caudal rhombencephalon showing the site of Neurobiotin injection (merged, Neurobiotin green plus glutamate immunoreactivity red signals) into the vagal nucleus. $\boldsymbol{B}_{\mathbf{1}}-\boldsymbol{B}_{\mathbf{3}}$, Photomicrographs at a higher magnification of the portion of the transverse section indicated by the white rectangle in $\boldsymbol{B}$, showing retrogradely labeled neurons $\left(\boldsymbol{B}_{1}\right)$, glutamate immunoreactivity $\left(\boldsymbol{B}_{2}\right)$, and merged image $\left(\boldsymbol{B}_{\mathbf{3}}\right)$ at the level of the PTRG region. Retrogradely labeled neurons displaying immunoreactivity for glutamate are indicated by white arrows. V, Trigeminal motor nucleus; VII, facial motor nucleus; IX, glossopharyngeal motor nucleus; $X$, vagal motor nucleus. Scale bars: $\boldsymbol{B}, \boldsymbol{C}, 200 \mu \mathrm{m} ; \boldsymbol{B}_{\mathbf{1}}-\boldsymbol{B}_{3}, 100 \mu \mathrm{m}$.
A

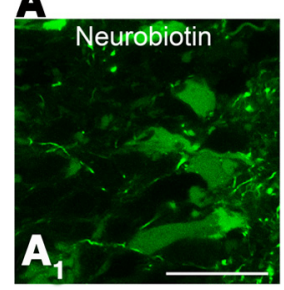

B Control

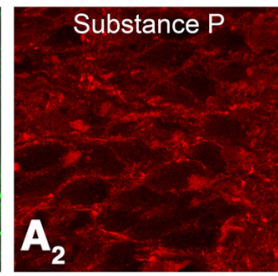

$1 \mathrm{mM} C N Q X+$ $1 \mathrm{mM} C N Q \mathrm{X}+$
$5 \mathrm{mM}$-AP5

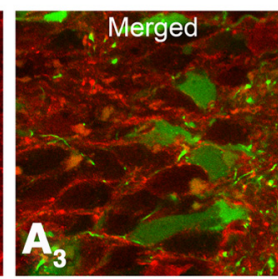

$1 \mu \mathrm{M} \mathrm{SP}$

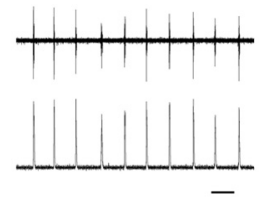

$\overline{1 \mathrm{~s}}$

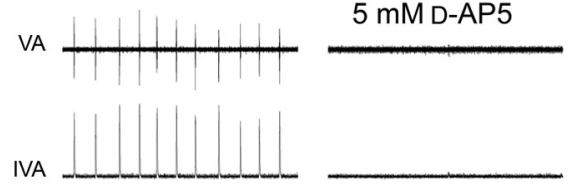

Figure 5. Rhythmogenic role of substance $P$. $A$, Substance $P$ immunoreactivity within the pTRG. Confocal photomicrographs showing retrogradely labeled neurons $\left(A_{1}\right.$, green signal) after injections of Neurobiotin into the vagal motoneuron pool, substance $P$ immunoreactivity $\left(A_{2}\right.$, red signal), and merged image $\left(A_{3}\right)$. Note the presence within the pTRG region of some retrogradely labeled neurons surrounded by substance $P$-immunoreactive structures. Scale bar: $A_{1}-A_{3}, 30 \mu \mathrm{m}$. $B$, Bilateral microinjections of $1 \mathrm{~mm}$ CNQX/5 mM D-AP5 into the pTRG abolished the respiratory rhythm that was restored $\sim 1$ min after bilateral microinjections of $1 \mu \mathrm{m}$ substance $P(S P)$ into the same site. VA, Raw vagal nerve activity; IVA, integrated vagal nerve activity.

those already described for Neurobiotin-labeled neurons. As expected, detectable $\alpha$-bungarotoxin binding sites (green signal) were found in the pTRG area (Fig. $6 B_{2}$ ). They were associated with the soma of retrogradely labeled neurons (Fig. $6 B_{3}$, merged image) projecting to the vagal motoneuronal pool.

Bilateral microinjections of $1 \mathrm{~mm}$ nicotine $(0.5-1 \mathrm{pmol})$ performed into the pTRG $(n=3) \sim 2$ min after the onset of apnea induced by bilateral microinjections of $1 \mathrm{~mm}$ CNQX/5 mM D-AP5 into the same region caused a resumption of rhythmic respiratory activity within $1 \mathrm{~min}$ (Fig. 6C), as described previously with $\alpha 7$ nAChRs agonists (Mutolo et al., 2011). The recovered vagal mo- tor output displayed characteristics similar to those already reported for substance P. Bilateral microinjections of $1 \mathrm{~mm}$ nicotine (three trials) into control neighboring regions (see above) $0.4 \mathrm{~mm}$ or farther away from the pTRG were not able to restore rhythmic activity during apnea induced by the blockade of ionotropic glutamate receptors.

\section{Discussion}

Present results provide an anatomical and functional characterization of the pTRG region. By retrograde labeling, we found neurons projecting to vagal motoneurons located in the isthmic periventricular cell layer that can be easily identified by anatomical landmarks, such as a location dorsal to the isthmic Müller cell $\mathrm{I}_{1}$, the ARRN, and the sulcus limitans of His. The location of this region closely corresponds to that of the pTRG already defined in previous studies (Mutolo et al., 2007, 2010, 2011). The results obtained with microinjections of several neuroactive drugs exactly into this region in the present investigation as well as in previous studies (Mutolo et al., 2007, 2010, 2011) support the notion that the pTRG corresponds to the respiratory CPG. Neurons located in the pTRG (possibly premotor neurons) mainly project to the ipsilateral vagal motor nucleus but also have projections to the contralateral side in agreement with previous findings (Rovainen, 1985; Thompson, 1985; Russell, 1986; Gariépy et al., 2012a). The morphology and location of the retrogradely labeled pTRG neurons observed in our experiments correspond to one of the two retrogradely labeled neuronal populations described by Gariépy et al. (2012b), i.e., that located in the isthmic periventricular cell layer close to the sulcus limitans of His, named by Gariépy et al. (2012b) as the "dorsal respiratory MLR." Gariépy et al. (2012a) also reported that, after fairly extensive injections at the level of the glossopharyngeal motor nucleus, they identified a group of larger neurons with respiratory activity (retrogradely stained) located caudolateral to their dorsal MLR and in a paratrigeminal location. Moreover, they reported that their dorsal respiratory MLR project to this latter group, which they refer to as pTRG (different from the pTRG discussed here). This group of neurons (their pTRG) was not identified by our injections into the vagal nucleus that only stained neurons in the area of their dorsal MLR (our pTRG). We did not find retrogradely labeled neurons in the more caudolateral group, because we did not perform microinjections specifically into the glossopharyngeal motor nucleus. The location of their dorsal MLR corresponds to that of the pTRG region described in the present study and by Mutolo et al. $(2007,2010,2011)$. Whereas Gariépy et al. (2012b) have regarded the dorsal respiratory MLR as an input structure to the respiratory CPG at a caudolateral location (their pTRG), we show that the pTRG identified in the present study fulfills all criteria of being the respiratory CPG. Except for this difference in interpretation attributable to the new results, our findings agree in many respects with the results of Gariépy et al. (2012b).

The results obtained by blockade or activation of the pTRG support the hypothesis that this region is critical for the generation of respiratory activity (Mutolo et al., 2007, 2010, 2011; 
Gariépy et al., 2012a). In fact, apnea caused by bath application of CNQX/DAP5 (Bongianni et al., 1999; Mutolo et al., 2011) or muscimol (Bongianni et al., 2006) was mimicked by very restricted unilateral microinjections of the same drugs into this region. Bilateral projections of pTRG neurons to respiratory motoneurons (present findings) as well as crossed connections between the caudolateral group of cells (Gariépy et al., 2012a) may explain the bilateral effects obtained by unilateral pTRG microinjections. In agreement with the view that changes in respiratory frequency are attributable to an action on the central mechanisms generating the respiratory rhythm (Gray et al., 1999; Feldman and Del Negro, 2006; Bongianni et al., 2008), we observed that microinjections of the PTRG with glutamate agonists caused a marked increase in respiratory frequency associated with increases in peak amplitude and duration of vagal bursts.

pTRG contains glutamatergic neurons The present study is the first to provide evidence that pTRG neurons, retrogradely labeled from the vagus nucleus, are immunoreactive for glutamate, thus showing that glutamatergic transmission mediates the excitatory input to vagal motoneurons. Accordingly, a recent study reported the presence of numerous glutamatergic neurons in the isthmic region of the lamprey (Villar-Cerviño et al., 2013). Interestingly, in the pTRG region, there are also glutamate-expressing cells, not retrogradely labeled, that may represent interneurons of the respiratory CPG. To what degree the rhythm generation depends on premotor neurons or possible interneurons cannot be determined at this stage. These findings along with the apneic response induced by an NMDA and AMPA receptor blockade strongly support the involvement of glutamatergic mechanisms in the respiratory rhythmogenesis.

\section{Substance $P$ innervation of the respiratory $C P G$}

The present findings demonstrate the presence of an intense substance $\mathrm{P}$ immunoreactivity in close proximity to neurons projecting to the vagal motoneuronal pool and also around pTRG cells not retrogradely labeled. Consistently, the respiratory rhythm can be restored by substance P microinjected into the pTRG during apnea induced by bilateral microinjections of CNQX/D-AP5, thus confirming the crucial importance of this region in respiratory rhythm generation. Unfortunately, a method for the identification of neurons expressing neurokinin 1 receptors considered to be a marker for the respiratory rhythm generator of mammals (Gray et al., 1999, 2001; Guyenet et al., 2002; Feldman and Del Negro, 2006) is not available in the lamprey. In this context, it should be recalled that tachykinin immunoreactivity is widely distributed in the CNS of the lampreys (Nozaki and Gorbman,
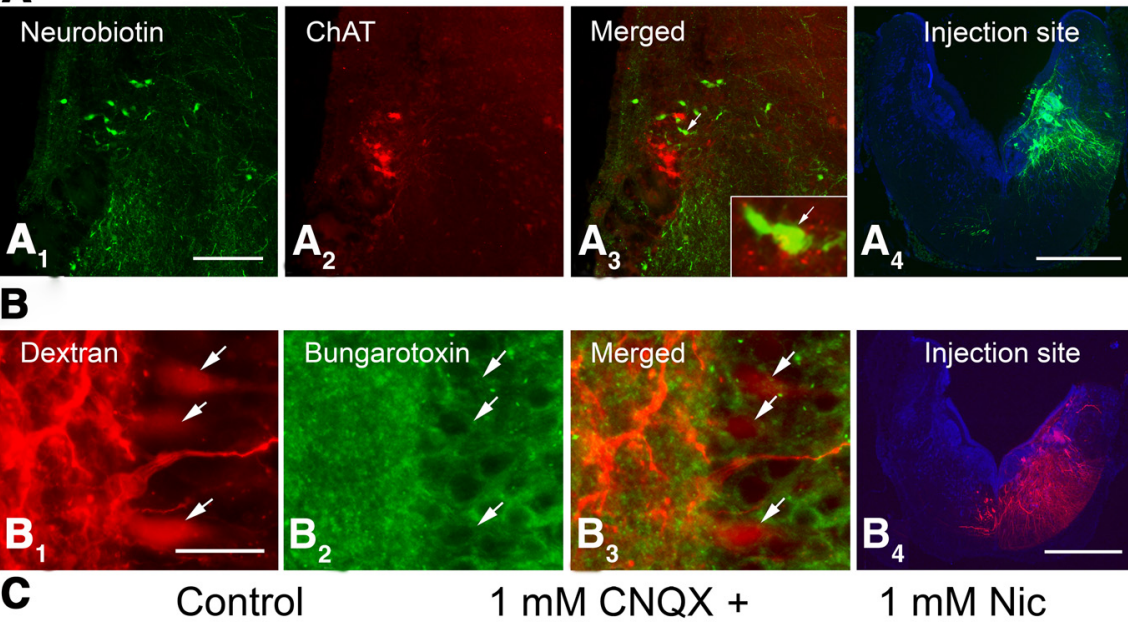

$1 \mathrm{mM} \mathrm{CNQX}+$

$5 \mathrm{mM}$ D-AP5

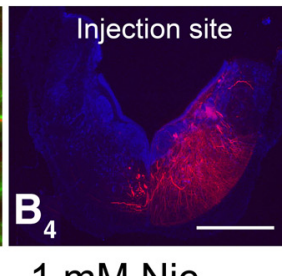

$1 \mathrm{mM} \mathrm{Nic}$
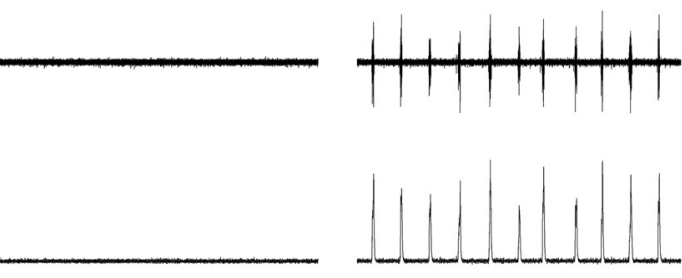

$\overline{1 \mathrm{~s}}$

Figure 6. Rhythmogenic role of acetylcholine. $A$, Immunofluorescent labeling of ChAT-expressing neurons in the pTRG area. $A_{\boldsymbol{1}}$, Photomicrographs of retrogradely labeled neurons (green signal) after injections of Neurobiotin into the region of vagal motoneurons. $A_{2}$, ChAT immunostaining (red signal). $\boldsymbol{A}_{3}$, Merged image. Note the presence of a small population of cholinergic cells a d in showing the site

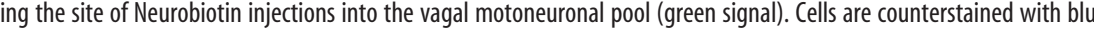
CNQX/5 mM D-AP5 into the $\mathrm{pTRG}$ abolished the respiratory rhythm that was restored $\sim 1 \mathrm{~min}$ after bilateral microinjections of $1 \mathrm{~mm}$ nicotine (Nic) into the same sites. VA, Raw vagal nerve activity; IVA, integrated vagal nerve activity.

1986; Yáñez et al., 1999; Auclair et al., 2004) and that a comparison with mammals and other vertebrates suggests that the pattern of its distribution is highly maintained throughout evolution. Although two populations of tachykinin-containing neurons exist in the rostral rhombencephalon (Auclair et al., 2004), the source of endogenous substance $P$ within the pTRG region is not known.

\section{Cholinergic innervation of the respiratory CPG}

In agreement with recent findings on the excitatory role of acetylcholine on respiration (Mutolo et al., 2011), cholinergic neurons have been found close to and intermingled with vagalprojecting PTRG neurons possibly making synaptic contacts on their soma, thus suggesting that separate glutamatergic and cholinergic neurons exist. These results are consistent with previous findings (Pombal et al., 2001; Le Ray et al., 2003) showing ChATimmunoreactive cells close to the isthmic Müller cells, i.e., in the vicinity of a region that well corresponds to the pTRG. Furthermore, we provide evidence that $\alpha$-bungarotoxin binding sites (nAChRs) are present in the pTRG area, in particular associated with the soma of retrogradely labeled neurons. Combined histo- 
logical and functional findings of the present study strongly suggest that pTRG neurons expressing $\alpha 7 \mathrm{nAChRs}$ may have a rhythmogenic role. Because of the potent modulatory control on respiratory activity exerted by substance $\mathrm{P}$ and nicotine/acetylcholine, we propose that microinjections of these drugs could represent useful tools for the functional identification of the pTRG.

\section{Mechanisms underlying respiratory rhythm resumption}

The results on the resumption of respiratory rhythm after substance $\mathrm{P}$ or nicotine microinjections into the pTRG are intriguing but difficult to interpret. These findings resemble the "grouppacemaker" hypothesis proposed for respiratory rhythm generation in mammals (Del Negro et al., 2005; Feldman and Del Negro, 2006). It was found that a blockade of burst-promoting currents eliminates the respiratory rhythm that, however, could be restored by increasing network excitability by exogenous excitatory agents (Del Negro et al., 2005; Feldman and Del Negro, 2006). The hypothesis proposed that the resumption of respiratory rhythmic activity resulted from synaptic glutamatergic interconnections that combine with the intrinsic membrane properties of neurons without the involvement of pacemaker neurons. However, in our experimental conditions, ionotropic glutamate receptors within the pTRG were blocked by CNQX/D-AP5. Therefore, excitatory interconnections could be provided by metabotropic glutamate receptors (Pace et al., 2007; BenMabrouk et al., 2012) or, alternatively, by gap junction coupling of glutamatergic neurons (Elsen et al., 2008). An involvement of metabotropic glutamate receptors that have an excitatory modulatory role on the lamprey respiratory activity (Bongianni et al., 2002) seems unlikely because their blockade during a concurrent removal of fast synaptic excitatory and inhibitory transmission did not cause any change in respiratory activity (Mutolo et al., 2011). The role of gap junctions in the lamprey respiratory rhythm generation is at present unknown. It is also possible that the resumption of respiratory rhythm induced by substance $\mathrm{P}$ may depend on an increase in an $I_{\mathrm{CAN}}$-dependent bursting mechanism (Peña and Ramirez, 2004; Ben-Mabrouk and Tryba, 2010). Furthermore, nicotine could have restored rhythmic activity by increasing pTRG neuron excitability via a $\mathrm{Ca}^{2+}$-dependent mechanism (for review, see Albuquerque et al., 2009). In conclusion, the reasons underlying respiratory rhythm resumption remain unclear.

\section{The link between locomotor and respiratory activity}

Garièpy et al. (2012a,b) have shown that, in lamprey as well as other vertebrates, an enhanced locomotor activity also leads to an enhanced respiratory activity. They have ascribed the link between the two commands to their dorsal respiratory MLR, which would affect downstream respiratory structures. With our current findings, we show that this area corresponds to the pTRG and thus actually qualifies as the respiratory CPG itself. Most likely, the input from the ventrally located MLR (locomotor command) will directly interact with its dorsal neighbor controlling the respiratory activity.

\section{Similarities between the pTRG and mammalian respiratory networks}

We believe that the PTRG has a crucial role in respiratory rhythm generation similar to that of the preBötC in mammals (Smith et al., 1991; Feldman and Del Negro, 2006). Like the pTRG (Mutolo et al., 2007, 2010), the preBötC contains neurons specifically sensitive to opioids, and substance $\mathrm{P}$ that modulates the respiratory frequency is considered essential for the respiratory rhythm generation (Gray et al., 1999, 2001). In addition, preBötC neurons expressing neurokinin 1 receptors are predominantly glutamatergic and comprise subpopulations of respiratory premotor neurons (Guyenet et al., 2002). A possible difference is that the lamprey respiratory oscillator is located in the rostral rhombencephalon/isthmic region corresponding to the rostral pons, whereas the glutamate respiratory rhythmogenic network described in rodents, i.e., the preBötC, is located in the medulla (Champagnat et al., 2011). It is also plausible that the basic oscillatory and neuromodulatory mechanisms in the respiratory network are evolutionary conserved regardless of their location and their inspiratory or expiratory function. Interestingly, the embryonic/neonatal or juvenile retrotrapezoid nucleus/parafacial respiratory group expiratory oscillator consists of glutamatergic neurons that express neurokinin1 receptors (Mulkey et al., 2004; Onimaru et al., 2008; Takakura et al., 2008; Lazarenko et al., 2009; Thoby-Brisson et al., 2009; for review, see Guyenet and Mulkey, 2010; Feldman et al., 2013). In addition, burst activity in this oscillator may involve endogenous $I_{\mathrm{NaP}}$-dependent bursting properties (Fortin and Thoby-Brisson, 2009; Thoby-Brisson et al., 2009; Molkov et al., 2010).

\section{Conclusions}

Because of the several neuroanatomical markers characterizing the pTRG region and the results obtained by focal blockade or activation of pTRG neurons as well as the absence of respiratory effects in response to microinjections into neighboring regions, we are confident that our localization of the pTRG corresponds to that of the respiratory CPG. The results support the notion that the basic organization and main functional characteristics of the neuronal network subserving respiratory rhythm generation are highly conserved throughout phylogeny (Kinkead, 2009), in agreement with the conclusions of several previous studies on other lamprey neural structures (Grillner, 2006; Robertson et al., 2007; Ericsson et al., 2011, 2013; Stephenson-Jones et al., 2011, 2012a,b).

\section{References}

Albuquerque EX, Pereira EF, Alkondon M, Rogers SW (2009) Mammalian nicotinic acetylcholine receptors: from structure to function. Physiol Rev 89:73-120. CrossRef Medline

Auclair F, Lund JP, Dubuc R (2004) Immunohistochemical distribution of tachykinins in the CNS of the lamprey Petromyzon marinus. J Comp Neurol 479:328-346. CrossRef Medline

Ben-Mabrouk F, Tryba AK (2010) Substance P modulation of TRPC3/7 channels improves respiratory rhythm regularity and ICAN-dependent pacemaker activity. Eur J Neurosci 31:1219-1232. CrossRef Medline

Ben-Mabrouk F, Amos LB, Tryba AK (2012) Metabotropic glutamate receptors (mGluR5) activate transient receptor potential canonical channels to improve the regularity of the respiratory rhythm generated by the pre-Botzinger complex in mice. Eur J Neurosci 35:1725-1737. CrossRef Medline

Bongianni F, Deliagina TG, Grillner S (1999) Role of glutamate receptor subtypes in the lamprey respiratory network. Brain Res 826:298-302. CrossRef Medline

Bongianni F, Mutolo D, Carfì M, Pantaleo T (2002) Group I and II metabotropic glutamate receptors modulate respiratory activity in the lamprey. Eur J Neurosci 16:454-460. CrossRef Medline

Bongianni F, Mutolo D, Nardone F, Pantaleo T (2006) GABAergic and glycinergic inhibitory mechanisms in the lamprey respiratory control. Brain Res 1090:134-145. CrossRef Medline

Bongianni F, Mutolo D, Cinelli E, Pantaleo T (2008) Neurokinin receptor modulation of respiratory activity in the rabbit. Eur J Neurosci 27:32333243. CrossRef Medline

Champagnat J, Morin-Surun MP, Bouvier J, Thoby-Brisson M, Fortin G 
(2011) Prenatal development of central rhythm generation. Respir Physiol Neurobiol 178:146-155. CrossRef Medline

Csillik B, Nemcsók J, Chase B, Csillik AE, Knyihár-Csillik E (1999) Infraterminal spreading and extrajunctional expression of nicotinic acetylcholine receptors in denervated rat skeletal muscle. Exp Brain Res 125:426-434. CrossRef Medline

Del Negro CA, Morgado-Valle C, Hayes JA, Mackay DD, Pace RW, Crowder EA, Feldman JL (2005) Sodium and calcium current-mediated pacemaker neurons and respiratory rhythm generation. J Neurosci 25: 446-453. CrossRef Medline

Elsen FP, Shields EJ, Roe MT, Vandam RJ, Kelty JD (2008) Carbenoxolone induced depression of rhythmogenesis in the pre-Botzinger complex. BMC Neurosci 9:46. CrossRef Medline

Ericsson J, Silberberg G, Robertson B, Wikström MA, Grillner S (2011) Striatal cellular properties conserved from lampreys to mammals. J Physiol 589:2979-2992. CrossRef Medline

Ericsson J, Stephenson-Jones M, Kardamakis A, Robertson B, Silberberg G, Grillner S (2013) Evolutionarily conserved differences in pallial and thalamic short-termsynaptic plasticity in striatum. J Physiol 591:859-874. CrossRef Medline

Feldman JL, Del Negro CA (2006) Looking for inspiration: new perspectives on respiratory rhythm. Nat Rev Neurosci 7:232-242. CrossRef Medline

Feldman JL, Del Negro CA, Gray PA (2013) Understanding the rhythm of breathing: so near, yet so far. Annu Rev Physiol 75:423-452. CrossRef Medline

Fortin G, Thoby-Brisson M (2009) Embryonic emergence of the respiratory rhythm generator. Respir Physiol Neurobiol 168:86-91. CrossRef Medline

Gariépy JF, Missaghi K, Chartr é S, Robert M, Auclair F, Dubuc R (2012a) Bilateral connectivity in the brainstem respiratory networks of lampreys. J Comp Neurol 520:1442-1456. CrossRef Medline

Gariépy JF, Missaghi K, Chevallier S, Chartré S, Robert M, Auclair F, Lund JP, Dubuc R (2012b) Specific neural substrate linking respiration to locomotion. Proc Natl Acad Sci U S A 109:E84-E92. CrossRef Medline

Gray PA, Rekling JC, Bocchiaro CM, Feldman JL (1999) Modulation of respiratory frequency by peptidergic input to rhythmogenic neurons in the preBötzinger complex. Science 286:1566-1568. CrossRef Medline

Gray PA, Janczewski WA, Mellen N, McCrimmon DR, Feldman JL (2001) Normal breathing requires preBötzinger complex neurokinin-1 receptorexpressing neurons. Nat Neurosci 4:927-930. CrossRef Medline

Grillner S (2003) The motor infrastructure: from ion channels to neuronal networks. Nat Rev Neurosci 4:573-586. CrossRef Medline

Grillner S (2006) Biological pattern generation: the cellular and computational logic of networks in motion. Neuron 52:751-766. CrossRef Medline

Guimond JC, Auclair F, Lund JP, Dubuc R (2003) Anatomical and physiological study of respiratory motor innervation in lampreys. Neuroscience 122:259-266. CrossRef Medline

Guyenet PG, Mulkey DK (2010) Retrotrapezoid nucleus and parafacial respiratory group. Respir Physiol Neurobiol 173:244-255. CrossRef Medline

Guyenet PG, Sevigny CP, Weston MC, Stornetta RL (2002) Neurokinin-1 receptor-expressing cells of the ventral respiratory group are functionally heterogeneous and predominantly glutamatergic. J Neurosci 22: 3806-3816. Medline

Jones IW, Wonnacott S (2004) Precise localization of $\alpha 7$ nicotinic acetylcholine receptors on glutamatergic axon terminals in the rat ventral tegmental area. J Neurosci 24:11244-11252. CrossRef Medline

Kinkead R (2009) Phylogenetic trends in respiratory rhythmogenesis: insights from ectothermic vertebrates. Respir Physiol Neurobiol 168:39-48. CrossRef Medline

Kumar S, Hedges SB (1998) A molecular timescale for vertebrate evolution. Nature 392:917-920. CrossRef Medline

Lazarenko RM, Milner TA, Depuy SD, Stornetta RL, West GH, Kievits JA, Bayliss DA, Guyenet PG (2009) Acid sensitivity and ultrastructure of the retrotrapezoid nucleus in Phox2b-EGFP transgenic mice. J Comp Neurol 517:69-86. CrossRef Medline

Le Ray D, Brocard F, Bourcier-Lucas C, Auclair F, Lafaille P, Dubuc R (2003) Nicotinic activation of reticulospinal cells involved in the control of swimming in lampreys. Eur J Neurosci 17:137-148. CrossRef Medline

Martel B, Guimond JC, Gariépy JF, Gravel J, Auclair F, Kolta A, Lund JP,
Dubuc R (2007) Respiratory rhythms generated in the lamprey rhombencephalon. Neuroscience 148:279-293. CrossRef Medline

Ménard A, Auclair F, Bourcier-Lucas C, Grillner S, Dubuc R (2007) Descending GABAergic projections to the mesencephalic locomotor region in the lamprey Petromyzon marinus. J Comp Neurol 501:260-273. CrossRef Medline

Molkov YI, Abdala AP, Bacak BJ, Smith JC, Paton JF, Rybak IA (2010) Lateexpiratory activity: emergence and interactions with the respiratory $\mathrm{CpG}$. J Neurophysiol 104:2713-2729. CrossRef Medline

Mulkey DK, Stornetta RL, Weston MC, Simmons JR, Parker A, Bayliss DA, Guyenet PG (2004) Respiratory control by ventral surface chemoreceptor neurons in rats. Nat Neurosci 7:1360-1369. CrossRef Medline

Mutolo D, Bongianni F, Einum J, Dubuc R, Pantaleo T (2007) Opioidinduced depression in the lamprey respiratory network. Neuroscience 150:720 729. CrossRef Medline

Mutolo D, Bongianni F, Cinelli E, Pantaleo T (2010) Role of neurokinin receptors and ionic mechanisms within the respiratory network of the lamprey. Neuroscience 169:1136-1149. CrossRef Medline

Mutolo D, Cinelli E, Bongianni F, Pantaleo T (2011) Identification of a cholinergic modulatory and rhythmogenic mechanism within the lamprey respiratory network. J Neurosci 31:13323-13332. CrossRef Medline

Nozaki M, Gorbman A (1986) Occurrence and distribution of substance P-related immunoreactivity in the brain of adult lampreys, Petromyzon marinus and Entosphenus tridentatus. Gen Comp Endocrinol 62:217-229. CrossRef Medline

Onimaru H, Ikeda K, Kawakami K (2008) CO2-sensitive preinspiratory neurons of the parafacial respiratory group express Phox $2 \mathrm{~b}$ in the neonatal rat. J Neurosci 28:12845-12850. CrossRef Medline

Pace RW, Mackay DD, Feldman JL, Del Negro CA (2007) Inspiratory bursts in the preBotzinger complex depend on a calcium-activated non-specific cation current linked to glutamate receptors in neonatal mice. J Physiol 582:113-125. CrossRef Medline

Peña F, Ramirez JM (2004) Substance P-mediated modulation of pacemaker properties in the mammalian respiratory network. J Neurosci 24 : 7549-7556. CrossRef Medline

Pombal MA, Marín O, González A (2001) Distribution of choline acetyltransferase-immunoreactive structures in the lamprey brain. J Comp Neurol 431:105-126. CrossRef Medline

Robertson B, Auclair F, Ménard A, Grillner S, Dubuc R (2007) GABA distribution in lamprey is phylogenetically conserved. J Comp Neurol 503:47-63. CrossRef Medline

Rovainen CM (1977) Neural control of ventilation in the lamprey. Fed Proc 36:2386-2389. Medline

Rovainen CM (1979) Neurobiology of lampreys. Physiol Rev 59:1007-1077. Medline

Rovainen CM (1983) Generation of respiratory activity by the lamprey brain exposed to picrotoxin and strychnine, and weak synaptic inhibition in motoneurons. Neuroscience 10:875-882. CrossRef Medline

Rovainen CM (1985) Respiratory bursts at the midline of the rostral medulla of the lamprey. J Comp Physiol A Neuroethol Sens Neural Behav Physiol 157:303-309. CrossRef Medline

Russell DF (1986) Respiratory pattern generation in adult lampreys (Lampetra fluviatilis): interneurons and burst resetting. J Comp Physiol A Neuroethol Sens Neural Behav Physiol 158:91-102. CrossRef Medline

Smith JC, Ellenberger HH, Ballanyi K, Richter DW, Feldman JL (1991) PreBotzinger complex: a brainstem region that may generate respiratory rhythm in mammals. Science 254:726-729. CrossRef Medline

Stephenson-Jones M, Samuelsson E, Ericsson J, Robertson B, Grillner S (2011) Evolutionary conservation of the basal ganglia as a common vertebrate mechanism for action selection. Curr Biol 21:1081-1091. CrossRef Medline

Stephenson-Jones M, Ericsson J, Robertson B, Grillner S (2012a) Evolution of the basal ganglia; dual output pathways conserved throughout vertebrate phylogeny. J Comp Neurol 520:2957-2973. CrossRef Medline

Stephenson-Jones M, Floros O, Robertson B, Grillner S (2012b) Evolutionary conservation of the habenular nuclei and their circuitry controlling the dopamine and 5-hydroxytryptophan (5-HT) systems. Proc Natl Acad Sci U S A 109:E164-E173. CrossRef Medline

Takakura AC, Moreira TS, Stornetta RL, West GH, Gwilt JM, Guyenet PG (2008) Selective lesion of retrotrapezoid Phox $2 \mathrm{~b}$-expressing neurons raises the apnoeic threshold in rats. J Physiol 586:2975-2991. CrossRef Medline 
Thoby-Brisson M, Karlén M, Wu N, Charnay P, Champagnat J, Fortin G (2009) Genetic identification of an embryonic parafacial oscillator coupling to the preBotzinger complex. Nat Neurosci 12:1028-1035. CrossRef Medline

Thompson KJ (1985) Organization of inputs to motoneurons during fictive respiration in the isolated lamprey brain. J Comp Physiol A Neuroethol Sens Neural Behav Physiol 157:291-302. CrossRef Medline

Villar-Cerviño V, Barreiro-Iglesias A, Fernández-López B, Mazan S, Rodicio
MC, Anadón R (2013) Glutamatergic neuronal populations in the brainstem of the sea lamprey, Petromyzon marinus: an in situ hybridization and immunocytochemical study. J Comp Neurol 521:522-557. CrossRef Medline

Yáñez J, Pombal MA, Anadón R (1999) Afferent and efferent connections of the parapineal organ in lampreys: a tract tracing and immunocytochemical study. J Comp Neurol 403:171-189. CrossRef Medline 